\title{
Numerical modeling and forecast of channel changes on the river Lena near city Yakutsk
}

\author{
Pavel Golovlyov $^{1}$, Ekaterina Kornilova ${ }^{1}$, Inna Krylenko ${ }^{1,2}$, Vitaly Belikov ${ }^{2}$, Aleksandr Zavadskii ${ }^{1}$, \\ Eugeniya Fingert $^{1,2}$, Natalya Borisova ${ }^{2}$, and Elizaveta Morozova ${ }^{1}$ \\ ${ }^{1}$ Faculty of Geography, Lomonosov Moscow State University, Moscow, 119991, Russia \\ ${ }^{2}$ Water Problems Institute, Russian Academy of Sciences, Moscow, 119333, Russia \\ Correspondence: Pavel Golovlyov (pavel_golovlev@list.ru)
}

Published: 1 August 2019

\begin{abstract}
STREAM_2D software package was applied to retrospective and predictive simulations of the Lena River near city Yakutsk hydraulic and channel changes during ice-free period. The modelling results indicate significant correspondence of simulated water discharges distribution and water levels with observed ones for the period 2001-2016. Model has captured main erosion and depositional zones observed in the 2009-2016 years. Combination of typical monthly average hydrographs of $1 \%, 10 \%$ and $50 \%$ return intervals was used as an initial parameter for 10-year channel changes forecast. According to the simulation results, degradation of the Adamovskaya branch will be continued, which is the most negative impact for the Yakutsk city infrastructure maintenance. At the end of the forecast period the equal distribution between Adamovskaya and Buorylarskaya channels is possible, which is a positive trend from the point of view of the city water supply system.
\end{abstract}

\section{Introduction}

In the city of Yakutsk on the Lena River numerous engineering and water facilities exist, for the safe operation of which it is necessary to take into account the peculiarities of the water and channel regime of the river. In recent years, an unfavourable situation for the entire water infrastructure of the city has been created in the territory, due to the fact that the river channel near the left bank, where the city is located, grows shallower, while the right branch develops and large forms of the channel topography also shift (Chalov, 2016). The above-mentioned re-formations of the channel lead to the displacement of the navigable fairway, which complicates the work of the port, leads to failure of the city water intake, and complications associated with the ferry crossing. For the first time the adverse channel changess effect on this section of the Lena River was discovered as early as the 1970s by the expedition of the Lomonosov Moscow State University, and even then were made forecasts, according to which the shallowing of the branches near the city was expected (Chalov, 2012). In connection with the existing problems of water use, different projects were performed for the preserving of the main flow in the city area. Large number of papers were devoted to the study of channel processes in this area (Chalov, 2012, 2016; Zaitsev and Chalov, 1989), both with hydrological model applications (Zaitsev et al., 2004). This study is aimed at the significantly larger extent of the modelling area and the considered period for study area on the base of STREAM_2D hydrodynamic model (Belikov and Kochetkov, 2014), adapted for the $75 \mathrm{~km}$ long Lena River section for the period 2001-2016 years. Due to its complexity, hydrodynamic models with movable bottom are mainly used for non-extended channel sections and/or for non-extended periods (Sloff et al., 2012; Horvat et al., 2015; Zhang et al., 2014), often the data about real channel changes for long period are not available for the channel deformation modelling block validation. Therefore, to apply the model for a complex channel and floodplains system of the Lena River near Yakutsk the first task was detailed model hydraulic calibration and validation. Next goal was validation of the channel deformation modelling through continuous simulation for the period between repeated channel surveys of 2009 and 2016 in order to assess the quality of the model's reproduction of the main trends in vertical channel changes. The final goal of the research was forecast estimations for the possible 
trends in channel changes over the next decade, especially in view of the difficult situation with the city's water supply due to the shallowing of the Adamovskaya channel closest to Yakutsk city.

\section{The study area}

The city Yakutsk, located in the Lena River valley in the area under study, is an old Russian city (founded in the 17th century), is now the administrative centre of the Sakha Republic. The city's population is about 300 thousand people. Within the considered section of the Lena River near Yakutsk city, three hydrological gauges are located (Fig. 1). The measuring discharges and water levels gauge in the village of Tabaga is located in the upper part of the studied reach. The Lena River basin area for the Tabaga gauge is $897000 \mathrm{~km}^{2}$. The water level measuring gauge of the Yakutsk city is situated in the middle part of the study area, the Kangalassy gauge is located at the lower boundary of the area (Fig. 1). The study section of the river is characterized by numerous ramifications, and is located between the Tabaginsky cliff at upstream and the Kangalassky cliff in the lower reaches, which limit the spread of the left bank floodplain and low terraces above the floodplain, as they are rocky capes. The width of the main channel of the Lena River in this section is 3.5-4 km.

Near the city of Yakutsk, the Ponomaryov Island (Fig. 1) divides the main channel into two branches, comparable in terms of width and water flow - the Adamovskaya and Buorylarskaya branches. The water content of the Adamovskaya branch, which is closest to the city, has recently been degraded due to less water coming there (Chalov, 2012). In this section the floodplain width is $6-7 \mathrm{~km}$, the floodplain height reaches $10 \mathrm{~m}$ above the low-water level, the floodplains are developed insignificantly and the city of Yakutsk is mainly located on unflooded elevations.

The annual water level regime of the Lena River near Yakutsk city is characterized by a pronounced rise of the water levels during the spring flood, including because of ice jams, significant and sharp rises in water levels during summer-autumn floods and a relatively low and stable level in the cold part of the year. The ice regime of the Lena River has a number of features that are caused by the severe, extremely continental climate and the spread of permafrost. The ice jams, lasting from one to $5 \mathrm{~d}$ emerge on average every 1 to 2 years near the Yakutsk city in the areas of channel ramifications.

The maximum water discharge was observed on 24 May $1966\left(50900 \mathrm{~m}^{3} \mathrm{~s}^{-1}\right)$; and in the last two decades close water discharges amounted to $49600 \mathrm{~m}^{3} \mathrm{~s}^{-1}$ were recorded on 11 June 2006 and 20 May 2010. In general, there is a statistically significant increase in both average annual and maximum water discharge, which becomes particularly important from the beginning of 21 st century.

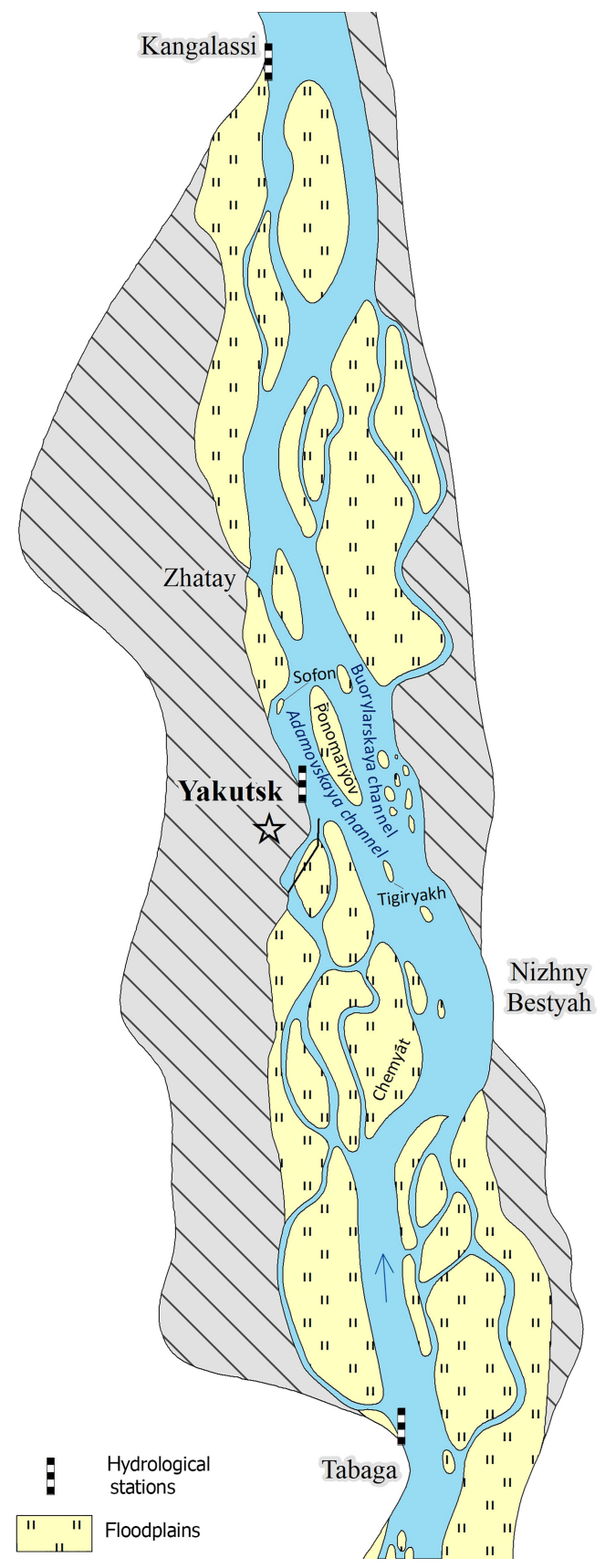

Figure 1. Study area.

\section{Methods and data}

STREAM_2D software package, widely used in Russia (Belikov et al., 2015), based on the numerical solution of twodimensional Saint-Venant equations in the "shallow water" approximation using hybrid computational grids of irregular structure and original topography interpolation algorithms (Belikov and Semenov, 2000) was used for modelling. This software showed high efficiency in modelling both for flow hydraulics and channel changes, including those for differ- 
ent key area in Russia (Volga, Ob, Lena, Kolyma, Vilyuy, Yana, Amur etc.) (Zaitsev et al., 2004; Belikov et al., 2002; Krylenko et al., 2018).

The description of the mathematical equations included in the numerical scheme of the model is presented, for example, in Belikov et al. (2015) and Aleksyuk and Belikov (2017). When modelling, a block of channel changes was involved, taking into account the convective transport of soil particles by flow, soaking up and sedimentation of sediments in an uneven flow, changing the bottom levels over time, taking into account the effect of flattening (transverse diffusion) of the underwater slope in a direction orthogonal to the velocity vector.

The initial data for the application of the hydrodynamic model were the materials of field researches of the soil erosion and channel processes laboratory at the Geography Faculty of Moscow State University, including the results of bathymetric surveys, measurements of water discharges, water levels and water slopes; daily regime observation data of hydrological gauges on the Lena rivers - Tabaga, Yakutsk, Kangalassi. To create the integrated digital topography models, the bathymetric survey data for 2009 and 2016 were integrated with the digital model of the floodplain topography, obtained in 2016 (based on topographic maps data and field surveys of the topography).

The map of jam-hazardous part of river channels was compiled on the basis of historical data and satellite images to set the places of ice jams formation, the dates of the ice jams formation were taken according to the hydrological gauges data.

The field data obtained during the expedition researches in 2016 was used to set the parameters of the channel-forming sediments fractions. Mainly the channel sediments are represented by the sand with an average diameter of $0.36 \mathrm{~mm}$, so the average diameter of the channel sediments was taken into account in the simulations.

At this stage, the modelling was carried out only for the warm high water period from 1 May to 31 October of each year, which covered the passage of the most important for the formation and displacement of the main channel forms of water flow floods and high waters.

\section{Results of calibration and validation of hydraulic characteristics}

The calibration and verification of the model was originally carried out based on data from 2016 field surveys, including a comparison of the water level marks along the longitudinal profiles and the distribution of the water discharges along the branches for various water discharges. When the roughness coefficients equal to $0.015-0.017$ for the channels and 0.05 for the floodplain, a good compliance was reached between the measured and calculated water levels at the control points. The difference between the modelled and observed water levels at the Yakutsk gauge was $1-4 \mathrm{~cm}$. On the average along the length of the study section, the difference between the values obtained during special expeditionary surveys (instantaneous water level measurements) and the results of modelling at control points did not exceed $10-18 \mathrm{~cm}$.

The model reproduces well the distribution of water discharges among the main branches (Table 1). In the main branching point near the Yakutsk city, which determines the water situation of the city, the Adamovskaya channel, closest to the city, receives $37 \%-39 \%$ of the input water discharge in the flow range from 9560 to $30000 \mathrm{~m}^{3} \mathrm{~s}^{-1}$ according to measurement data, the right Buorylarskaya channel gets up to $55 \%$ of the input flow, which reproduces the model. The remaining $7 \%$ of the input water flow goes along the Khatykhstakhaya channel, and the model slightly underestimates the water discharge in it (modelling value is $5 \%$ of the total water flow), which is due to the small detailing of the computational grid in this channel due to its insignificant width in comparison with the main channel.

Additional refinement of the roughness coefficients for the ice jams period at the hazardous sections according to the data for 2009-2015 was made to simulate water flow dynamics for the flood periods, and it was found that the best compliance of the water levels is provided with the roughness coefficients of the ice jams sections equal to 0.073 .

The simulation, based on data for the period from 20012015 , showed that the hydrodynamic model, adapted according to the field and regime observations data for 2009-2016, provides a steady good quality of water levels modelling over a long-term period, which confirms both by visual match of the graphs of the observed and simulated water levels (Fig. 2), and high values of the simulation quality criterion. The criterion of Nash-Sutcliffe (NSE) for the studied periods for the Lena River gauge in Yakutsk was 0.90 for 2001-2008 and 0.93 for 2009-2015 years (in the hydrological modelling practice it is assumed that the results with NSE $>0.75$ can be considered as good).

An additional validation of the model was carried out by comparing the simulated flooding boundaries with the flooding boundaries provided by satellite images (more than 20 images). It was found that the relative error when comparing the real hydrological situations observed by modeling and interpreting satellite images the divergence of flooded areas does not exceed $10 \%$ during floods and high waters and the maximum divergence reaches $18 \%$ during ice jams (Kornilova et al., 2018).

\section{Validation of the channel changes modelling results for the historical period}

Due to the presence of multi-temporal bathymetric surveys, both actual and model bottom evolution were evaluated for the period 2009-2016. Despite some limitations of model simulations (only the warm period of the years were mod- 
Table 1. Flow distribution according observation and modeling.

\begin{tabular}{|c|c|c|c|c|c|c|c|c|c|c|c|c|c|}
\hline \multirow[t]{3}{*}{ No. } & \multirow{3}{*}{$\begin{array}{l}\text { Date } \\
\text { Section }\end{array}$} & \multicolumn{4}{|c|}{1 Jun 2016} & \multicolumn{4}{|c|}{2 Jul 2016} & \multicolumn{4}{|c|}{19 Aug 2016} \\
\hline & & \multicolumn{2}{|c|}{$Q_{\mathrm{obs}}$} & \multicolumn{2}{|c|}{$Q_{\text {sim }}$} & \multicolumn{2}{|c|}{$Q_{\mathrm{obs}}$} & \multicolumn{2}{|c|}{$Q_{\text {sim }}$} & \multicolumn{2}{|c|}{$Q_{\text {obs }}$} & \multicolumn{2}{|c|}{$Q_{\text {sim }}$} \\
\hline & & $\mathrm{m}^{3} \mathrm{~s}^{-1}$ & $\%$ & $\mathrm{~m}^{3} \mathrm{~s}^{-1}$ & $\%$ & $\mathrm{~m}^{3} \mathrm{~s}^{-1}$ & $\%$ & $\mathrm{~m}^{3} \mathrm{~s}^{-1}$ & $\%$ & $\mathrm{~m}^{3} \mathrm{~s}^{-1}$ & $\%$ & $\mathrm{~m}^{3} \mathrm{~s}^{-1}$ & $\%$ \\
\hline 1 & Input discharge & 30000 & 100 & 30000 & 100 & 18840 & 100 & 18840 & 100 & 9560 & 100 & 9560 & 100 \\
\hline 2 & $\begin{array}{l}\text { Main channel near } \\
\text { isl. Elovy }\end{array}$ & 19800 & 66 & 20248 & 67.5 & - & - & 15134 & 80.3 & - & - & 9041 & 94.6 \\
\hline 3 & $\begin{array}{l}\text { Buorylarskaya } \\
\text { channel }\end{array}$ & 16500 & 55 & 16564 & 55.2 & 9951 & 53 & 9936 & 52.7 & 5229 & 55 & 5322 & 55.7 \\
\hline 4 & $\begin{array}{l}\text { Adamovskaya } \\
\text { channel }\end{array}$ & 11100 & 37 & 11549 & 38.5 & 7305 & 39 & 7537 & 40.0 & 3604 & 38 & 3800 & 39.7 \\
\hline 5 & $\begin{array}{l}\text { Khatykhstakhaya } \\
\text { channel }\end{array}$ & 2400 & 8 & 1545 & 5.2 & 1357 & 7 & 960 & 5.1 & 686 & 7 & 400 & 4.2 \\
\hline 6 & $\begin{array}{l}\text { Right channel near } \\
\text { isl. Sakhalin }\end{array}$ & 7500 & 25 & 8543 & 28.5 & 4241 & 23 & 5392 & 28.6 & 2897 & 30 & 2924 & 30.6 \\
\hline 7 & Zhatay channel & 7200 & 24 & 5500 & 18.3 & 2397 & 13 & 2307 & 12.2 & 629 & 7 & 575 & 6.0 \\
\hline 8 & $\begin{array}{l}\text { Main channel near } \\
\text { isl. Kopilka }\end{array}$ & 24300 & 81 & 25272 & 84.2 & - & - & 16883 & 89.6 & - & - & 9340 & 97.7 \\
\hline
\end{tabular}

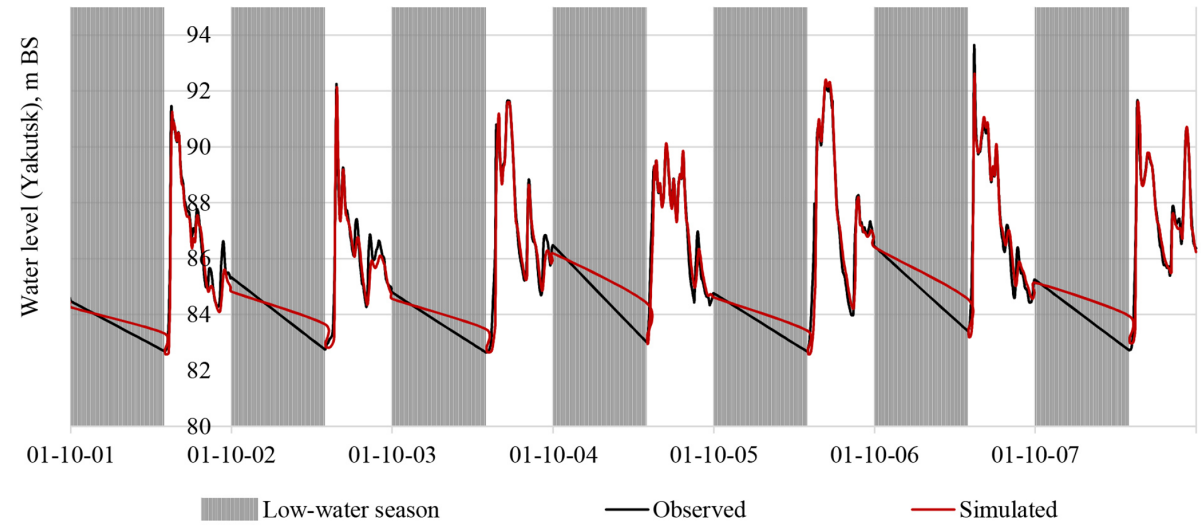

Figure 2. Observed and modelled water levels at the Yakutsk gauge at 2001-2008 (ice-free periods).

elled, sediments were considered as homogenous), the main positive result was the correspondence of the simulated and observed main zones of erosion and deposition (Fig. 3). Totally, in the $70 \%$ of modeling sells inside the channels deposition or erosion zones coincide with estimated according bathymetry surveys. But one can notice some alternation of sections with almost complete coincidence of the situation of the simulated and actual changes and areas, where the model reproduced not so good (Fig. 3).

The model adequate showed the channel changes in the upstream part of the studied section from the Tabaga until the island Chemyat. Downstream from this part of the channel model indicated erosion zone near the right steep bank, but in reality there are deposition zone. The possible reason of this discrepancy can be that the model is underestimated planform channel changes, which took more flow energy. There is the vast deposition zone near the Tigiryakh island. The stable two-stream system has formed near this is- land in the last decade, which is of decisive importance for the channel processes within the Yakutsk. In this area, the model again showed a situation close to reality. The obtained distribution of water flow along the branches corresponds to that observed in the 2016 year (the flow discharge was distributed equally among the right and left main branches). Unfortunately, in the next section from the island Tigiryakh to Ponomarev island, which is the most difficult for modelling because of the diversity channel processes factors, the simulation results can only be called partially successful. The model showed erosion along the left bank, but did not identify it in the central part of the channel. Despite the strong discrepancy between the actual and model data, the distribution of water flow between Adamovskaya and Buorylarskaya branches coincides with the observed $(39 \%$ and $51 \%$ correspondingly). Along the Adamovskaya and Buorylarskaya channels, the model has demonstrated quite realistic results. In the downstream section of the Lena River near Zhatay 

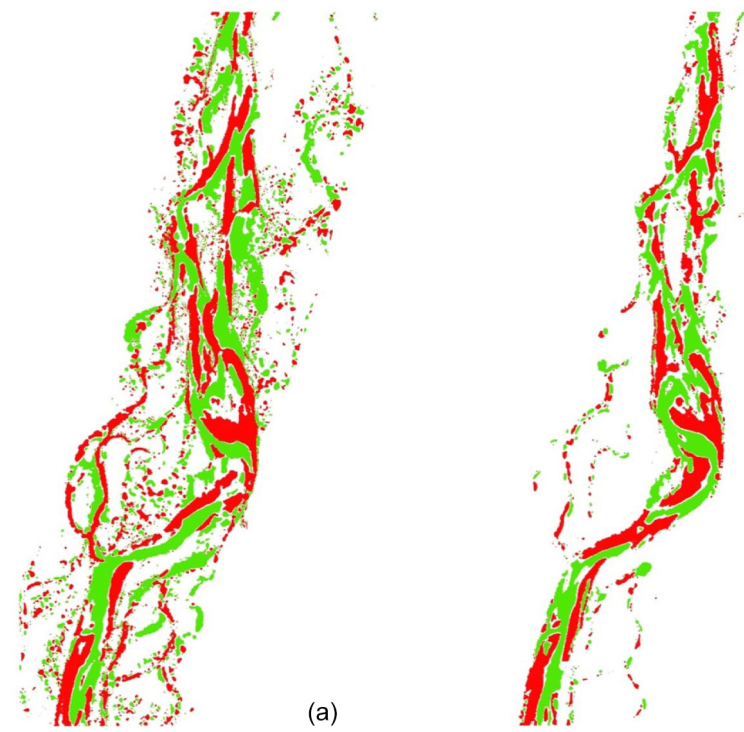

(b)

Figure 3. Deposition (shown in green colour) and erosion (shown in red colour) zones in the Lena River channel for the period 20092016 year according observation data (a) and modelling (b).

$75 \%$ of the flow is going in the main stream. Modelling on this section showed a result that is different from the observed one. This section is characterized by the maximum rate of planform changes. Thus, we can conclude about the connection of "unsuccessful" simulation results in some sections with the determining role of planform changes in these sections. The further development of the model should take into account planform channel deformation block improvement, including taking into account transverse circulation in water flow. Some discrepancies between model results and real changes can be connected with neglecting of the presence of permafrost, which is very difficult to take into account in such kind of modelling.

\section{Channel evolution forecast}

Ten-year prediction of channel changes of the Lena River near Yakutsk city considered the combination of typical hydrographs of different probabilities $(50 \%, 10 \%, 1 \%)$. The input hydrographs for each year was built on the base of monthly averages discharges (with the exception of 6 winter months from November to April). Then from these annual stepped hydrographs a combined hydrograph was compiled for a ten-year period in the following sequence: $50 \%, 10 \%$, $50 \%, 1 \%, 50 \%, 50 \%, 50 \%, 10 \%, 50 \%, 50 \%$. Further, this stepped hydrograph was approximated by a piecewise linear continuous equivalent hydrograph, which gave the averaged values of water discharges for each month coinciding with the monthly average discharge. The topography of the channel of 2016 was used as input in the beginning of the forecast period.

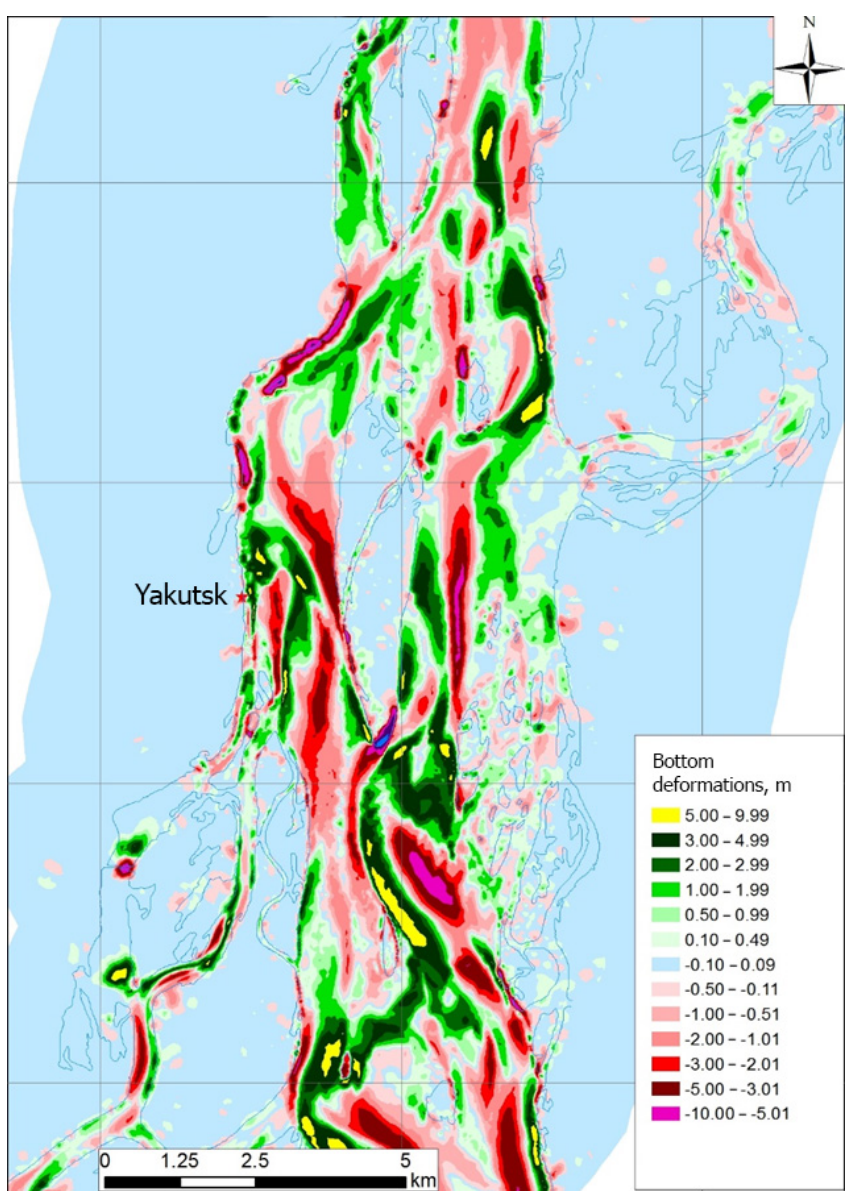

Figure 4. Simulated channel evolution near Yakutsk for the 10-year forecast period.

The simulation results for the forecast period showed (Fig. 4) that the left bank of the main channel noticeably erodes at the top of the Bestyakhskaya bend and downstream, the bank erosion line shifts downstream along with the displacement of the entire bend, which requires the development of bank protection measures due to the proximity of the highway. Previously, this section of the bank was already protected by spurs, but at present they are not effective due to the channel shift. At the same time, the right channel which is used for shipping presently below Nizhny Bestyah Island is activated and slightly straightened according to the simulation results, which allows to predict that in the coming years it will remain the most deep and navigable. The channel that straightens the bend in the area of the Chemyat Island is actively developing in the entrance, but then falls into the sediment deposition zone.

According to the simulation results for the 10-year forecast period, the Adamovskaya channel near Yakutsk will be degraded. This is have a harmfull effect to the maintenance of the city water intake system, due to the sandbar formation near the left bank and its downstream displacement (by ap- 


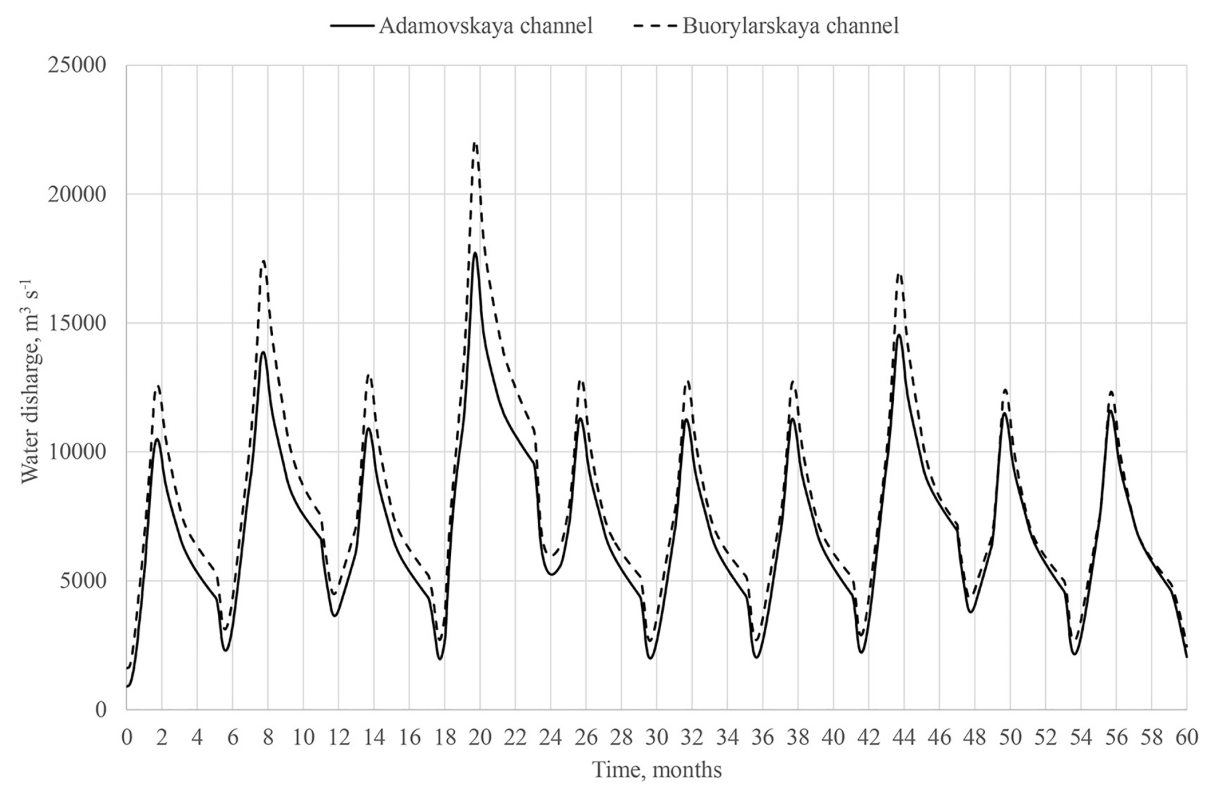

Figure 5. Distribution of water discharges between Adamovskaya and Buorylarskaya channels for 10-year forecast period.

proximately $500-800 \mathrm{~m}$ for 10 years). This will lead to huge deposition at the Yakutsk river harbour, and blocking of the clean water to the water intake from the main channel in the winter low-water period. At the same time, the intensive erosion of the bottom on the right side of the Adamovskaya channel (near the Ponomarev Island) and the displacement of the line of maximum depths from the left bank of the Adamovskaya channel (i.e. from the Yakutsk city) to the island will continue.

The upper part of the Ponomarev Island is intensively eroded, and downstream the Sofon Island is intensively eroded too (Fig. 4). The forecasts show that the last one will disappear due to erosion. If we analyse the diagram of water discharges distribution at the bifurcation nod of the Ponomarev Island (Fig. 5) over the ten-year forecast period, it is clear that at present about $10 \%-15 \%$ less water goes to the Adamovskaya channel than to the Buorylararskaya. However, after 10 years the water discharges are almost equal. This is due to an increase of a massive side bank in the right channel, which begins to block the entry into the Buorylarskaya channel, which is clearly seen in Fig. 5. This tendency will create some advantages perspective in the city water supply.

Intensive erosion is predicted in the area of the Zhatay village, approximately $2 \mathrm{~km}$ below the village, on the right bank of the main channel. At the same time, the process of alluviating of the access channel to the boatyard of the Zhataisky ship-repairing plant will continue, which requires conducting of the channel-improvement measures.

\section{Conclusions}

The numerical two-dimensional hydrodynamic model of the Lena River near Yakutsk city was developed, calibrated, and verified using field data. The model successfully reproduce the distribution water discharges among the channels, the water level regime for a long-term period and zones of inundation.

Comparison of modelled bottom changes with the observed ones for the period 2009-2015 has demonstrated that in the $70 \%$ of channel grid sells model adequately reproduce the erosion and deposition trends. In connection with the novelty of such studies for extended sections of large sections of lowland rivers, such results should be considered as positive.

Predictive simulations of the hydraulic flow regimes and the bottom evolution in the ice-free period were carried out on the basis of typical monthly average hydrographs of $1 \%$, $10 \%$ and $50 \%$ return intervals. Based on the simulation results, Adamovskaya channel will be further degraded, but to the end of 10 years forecast period the equalization of water discharges entering the Adamovskaya and Buorylarskaya channels is possible.

The channel development forecasts obtained as a result of the simulation served as the basis for the development of the hydrotechnical measures patterns to reduce the adverse effects of the channel processes for Yakutsk area.

The low-water (mostly subglacial) channel changes cover a much smaller part of the river channels and do not determine the main trends in the development of the channel. At the same time, the modelling of channel changes taking into account the ice cover as well as permafrost are separate, very 
complex and important tasks that are planned to be solved at the next stages of the studies, which are beyond the scope of this publication.

Data availability. Data available upon request to the contact author.

Author contributions. VB developed mathematical model, AZ, VB, IK developed experiment design, PG, EM prepared digital terrain models, PG, KE, IK, EF performed the simulations and result analysis, NB performed forecast simulations, AZ, EM analyzed historical channel changes.

Competing interests. The authors declare that they have no conflict of interest.

Special issue statement. This article is part of the special issue "Land use and climate change impacts on erosion and sediment transport". It is a result of the ICCE Symposium 2018 - Climate Change Impacts on Sediment Dynamics: Measurement, Modelling and Management, Moscow, Russia, 27-31 August 2018.

Acknowledgements. The authors of the article express their deep gratitude to the Laboratory of Soil Erosion and Channel Processes of the geographical faculty of Moscow State University for providing the field research materials.

Financial support. Simulation of the flow dynamics was supported by the Russian Foundation for Basic Research (grant RFBR no. 17-05-01230), the channel changes evaluation was supported by the Russian Science Foundation (grant RSF no. 18-17-00086).

\section{References}

Aleksyuk, A. I. and Belikov, V. V.: Simulation of shallow water flow with areas and bottom discontinuities, Comp. Math. Math. Phys., 57, 318-339, https://doi.org/10.1134/s0965542517020026, 2017.

Belikov, V. V. and Kochetkov, V. V.: Software Complex STREAM_2D to Calculate Streams, Bottom Deformation, and Pollutants Transfer in Open Flows, Software State Registration Certificate no. 612181, Russian Agency for Intellectual Property, 2014.

Belikov, V. V. and Semenov, A. Yu.: Non-Sibsonian interpolation of arbitrary system of points in Euclidean space and adaptive isolines generation, Appl. Numer. Math., 32, 371-387, 2000.

Belikov, V. V., Zaitsev, A. A., and Militeev, A. N.: Mathematical modeling of complex sections of large rivers channels, Water Resour., 29, 698-705, 2002 (in Russian).

Belikov, V. V., Krylenko, I. N., Alabyan, A. M., Sazonov, A. A., and Glotko, A. V.: Two-dimensional hydrodynamic flood modelling for populated valley areas of Russian rivers, Proc. IAHS, 370, 69-74, https://doi.org/10.5194/piahs-370-69-2015, 2015.

Chalov, R. S., Kirik, O. M., Ilyasov, A. K., and Botavin D. V.: Yakutsk water junction on the Lena river: problems of channel processes, history, modern times, prospects, management possibilities, Water Industry of Russia: problems, technologies, managemen, 3, 44-56, 2012 (in Russian).

Chalov, R. S., Zavadsky, A. S., Ruleva, S. N., Kirik, O. M., Prokop'ev, V. P., Androsov, I. M., and Sakharov, A. I.: Morphology, deformations, temporary changes in the channel of the Lena river and their influence on the economic infrastructure in the Yakutsk region, Geomorphology, 3, 22-35, 2016 (in Russian).

Horvat, Z, Horvat, M., and Spasojevic, M.: Two dimensional river flow and sediment transport model, Environ. Fluid Mech., 15, 595-625, https://doi.org/10.1007/s10652-014-9375-y, 2015.

Kornilova, E. D., Krylenko, I. N., Golovlyov, P. P., Sazonov, A. A., and Nikitsky, A. N.: Verification of the twodimensional hydrodynamic model of the Lena River near Yakutsk according to time-based space imagery data, Modern problems of remote sensing of the Earth from space, 15, 169-178, https://doi.org/10.21046/2070-7401-2018-15-5169-178, 2018 (in Russian).

Krylenko, I., Belikov, V., Fingert, E., Golovlyov, P., Glotko, A., Zavadskii, A., Samokhin, M., and Borovkov, S.: Analysis of the impact of hydrotechnical construction on the Amur river near Blagoveshchensk and Heihe cities using a twodimensional hydrodynamic model, Water Resour., 45, 112-121, https://doi.org/10.1134/S0097807818050378, 2018.

Sloff, K. and Mosselman, E.: Bifurcation modelling in a meandering gravel-sand bed river, Earth Surf. Proc. Land., 37, 15561566, https://doi.org/10.1002/esp.3305, 2012.

Zaitsev, A. A. and Chalov, R. S.: Channel processes and regulation of the river Lena in the area of Yakutsk, Water Resour., 5, 75-81 (in Russian), 1989.

Zaitsev, A. A., Belikov, V. V., and Militeev, A. N.: Using computer modeling for a large river, Proc. Int. Symp. "Sediment Transfer through the Fluvial System", Moscow, 2-6 August 2004, IAHS Publ. 288, ISBN 1-901502-67-8, 386-394, 2004.

Zhang, W., Xu, Y., Wang, Y., and Peng, H.: Modeling Sediment Transport and River Bed Evolution in River System, Journal of Clean Energy Technologies, 2, 175-179, 2014. 